a child's stature and weight are rapidly increasing. All the above causes are preventable; the curative element can be supplied by the local education authority in the form of physical training.

Group II.-The second large group of defects, causing one-third of the total rejections, consists chiefly of surgical diseases which are in great part amenable to treatment, especially if dealt with during school life. Under this heading we include: Loss and decay of many teeth, defects of vision and exbernal eye diseases, diseases of middle ear and deafness, hernia, and diseases of joints.

The "loss and decay of many teeth" has received as prominent a position in the reports of school medical officers as it makes for itself in the above table. As is well known, the treatment of dental caries in men going on active service is now being undertaken by the military authorities. It is hardly necessary to point out how much less expenditure would have been incurred (with a more satisfactory result for the individual) had preventive measures been adopted during school life; had a few visits then been paid to the school dental clinic, teeth might have been preserved, the functions of which must now be carried out by expensive dentures. School dental clinics have now been instituted (most of which are capable of performing a part only of the necessary work) by local education authorities in many areas-195 areas out of a total of 320 have as yet ${ }^{1}$ done nothing in the matter of providing school dental clinics.

Defective vision has from the first received considerable attention from school medical officers. By providing during early life suitable correction for errors of refraction we may subsequently find that the acuity of vision is improved and main. tained, thereby enabling more candidates to pass the Snellen type test, which is the only one used for examining recruits. In this connexion we might add that the schools for mothers and baby clinics now being formed in many areas should enable the medical officers to detect and treat children suffering from squint at an early age, and with a proportionately greater prospect of curing the squint and preserving vision in the squinting eye.

Ear diseases and deafness in the young if to be prevented or relieved must be dealt with in a thorough manner at an early stage. Children commencing attendance at school are only too often found to be suffering from an ear discharge of several years' standing; it is only widespread medical inspection of children under school age that will deal adequately with this complaint. Better results would thus be obtained in curing ear discharge, and, moreover, the risk of fatal complications diminished. In this connexion the School Medical Service might with advantage examine after their return to school those children who had suffered from such diseases as measles, scarlet fever, and whooping-cough.

Open-air schools will also have a beneficial influence in reducing the incidence of this serious complaint, for education carried on under such improved conditions has been shown to diminish the frequency of catarrhal conditions of the nasopharynx and of enlarged tonsils and adenoids, both of which conditions are well known to be precursors of middle-ear disease.

Many of the surgical conditions causing rejection of recruits, such as hernia, defects of extremities, \&c., could most advantageously be treated

1 See Annual Report of Chief Medical Officer of the Board of Education for 1913 . during school life; once the sufferer becomes a wage-earner he postpones the operation indefinitely because he grudges the time spent in "lying up." Moreover, the earlier these operations are performed the better it is for the development of the child; it seldom happens that a child with hernia is allowed to join in games with other children.

The present war has brought home to the nation the great importance of preventive medicine in dealing with germ diseases in a way nothing else could have done; widespread inoculation against typhoid fever, combined with improred camp hygiene, has reduced the losses from such preventable disease to smaller proportions than has been the case in any previous war. The facts brought forward by medical officers engaged in examining recruits equally with the reports of school medical officers supply ample evidence as to the existence of many preventable and curable physical defects among the children of the nation. In spite, therefore, of the fact that "exercise of the power to make arrangements for attending to the health of children" must lead to increased public expenditure, we may hope that more will be done to deal effectively with the preventable and curable defects which at present are inadequately dealt with either by preventive measures in the schools or treatment supplied by local authorities or voluntary charitable institutions.

Under the present conditions it is not possible for the School Medical Service to cover the ground. We may perhaps hope to see a Public Health Medical Service which would link itself with, and in part supersede, the existing public health and other organisations which already administer the inspection of midwives, the notification of births, the baby clinics and schools for mothers, school medical inspection, and the work of the factory surgeon. Medical officers of such a Public Health Medical Service would be offered work of considerable variety and interest, with a correspondingly increased power to improve the national physique.

\section{"TRANSIENT RENAL CONGESTION."}

By C. W. J. BRAsheR, M.D., Ch.B. BRIstol, LiEUTENaNT, R.A.M.C. (T.F.); PHYSICIAN TO OUT-Patients, BRistol ROYAL HOSPITAL FOR SICK CHILDREN AND WOMEN.'

BY an interesting coincidence Professor F. H. Edgeworth published in THE LANCET of July 10th (p. 72) a clinical note on Transient Renal Congestion and in the British Medical Journal of July 17th (p. 109) a special correspondent in Northern France makes brief allusion to a series of cases presenting a similar symptom-complex but with the addition of cedema, and he dignifies the condition with the title of a new disease.

Attention having been called to the subject by two writers it is probable that a number of other cases will be recorded, and it is only by the study of such a series that the claim to the title of a new disease can be established.

The following cases resemble Professor Edge. worth's :-

CASE 1. - The patient, aged 19 years, a thin, rather anæmic clerk, went for a 20-mile walk in the Cotswold Hills in cold weather on April 18th, 1903. In the evening he had some dysuria and noticed that his urine was dark red. Next day the urine was scanty and contained much blood and abundance of blood casts. In three days the free blood had 
disappeared, but there was a large amount of albumin and of epithelial casts. The urine gradually cleared and on April 29th (11 days from onset) it was free from albumin and casts. I advised him to avoid prolonged exercise in cold weather, but he went for another long walk on Jan. 9th, 1905, when the hæmaturia, \&c., recurred. On Jan. 19thi.e., 10 days after the attack-the urine was normal.

OASE 2.-The patient, aged 44 years, a man of good physique, but rather obese, with prematurely grey hair and well-marked "arcus senilis," complained of hæmaturia on Feb. 22nd, 1905. He had just returned from Clevedon, where he had been playing in a golf match in a cold wind and drizzling rain. The urine was scanty, deep red, and smoky, containing a large number of normal and brokenup red corpuscles and blood casts. The total quantity in the next 24 hours was under $25 \mathrm{oz}$. The blood gradually disappeared, but considerable quantities of albumin and of epithelial casts were present for three or four days. By Feb. 28th-i.e., six days after the onset - the urine was quite free from albumin and casts and was normal in quantity. He was warned against playing golf in cold weather, but he played again at Clevedon on Dec. 26th, 1911, and next day hæmaturia recurred. This attack followed a precisely similar course to the former and on Jan. 9th, 1912-i.e., 15 days after the onset-the urine was normal. There has been no recurrence.

CASE 3.- The patient, a healthy looking clerk aged 20 years, played cricket for the first time that season on a cold afternoon on June 13th, 1912, having changed from ordinary clothes to flannels. He said that he "shivered all the time" and about 9 P.M. passed a small quantity of urine "the colour of porter." Next day the urine was deep red in colour and contained a large precipitate of red corpuscles and of blood casts. This case followed a similar course to the others, and on June 24th-i.e., 11 days after the attack-the urine was normal.

All these cases resembled acute nephritis, but in none was any cdema observed. In this particular they are similar to Professor Edgeworth's cases, and the question arises-Does the presence of generalised cedema as observed in these recent cases in Northern France show that the latter are cases of true subacute nephritis as distinguished from "transient renal congestion"? In contrast to the above the following case is of interest.

CASE 4.-An athletic school boy, aged 16 years, entered an office on June 1st, 1910 ; finding the life too sedentary he cycled every evening and if overheated went for a swim afterwards. When seen on July 10th, 1910, he was passing per diem about 20-25 oz. of deep red urine containing a large amount of free blood, débris, and many blood and epithelial casts. He said he had noticed "a deposit like cocoa in the urine for about three weeks, but that he did not think it mattered." In spite of treatment and confinement to bed until April, 1913-i.e., for two and three-quarter years-his blood pressure has risen from 105 to $125 \mathrm{~mm}$. $\mathrm{Hg}$, and he still has 5 per cent. albumin and many hyaline casts containing atrophied epithelial cells in his urine. The case has drifted on to chronic parenchymatous nephritis, probably because he was not alarmed as were the others by hæmaturia and persisted in taking violent exercise.

Much has been written on the significance of albuminuria and its relation to nephritis, and many theories have been adranced; but the well-known instance of a Cambridge "eight" whose urine was tested and found to be normal before going for a hard row in cold weather and on their return seren of the crew had albuminuria, seems to suggest that there is an individual standard of resistance to the increased strain thrown on the kidneys by violent muscular exercise accompanied by rapid cooling of the body surface by perspiration in a cold atmosphere, and a blood pressure raised to an unknown degree. When this individual standard is exceeded the renal epithelium allows first an escape of albumin and then, if the strain be prolonged, hæmorrhages may occur either in the glomeruli or the tubules, or possibly in both. Such a strain may produce hæmaturia in one individual, epistaxis in another, and a troublesome bronchial cough with expectoration of blood-tinged mucus in a third. The writer has seen this last symptom on more than one occasion in men who have "rowed themselves out" in a hard race.

The analogy of "congestion of the lungs" may be adduced-although this term is usually only a euphemism for lobar pneumonia it will be generally admitted that true acute pulmonary congestion does occur. A patient is seen with all the clinical symptoms of early lobar pneumonia-fever, rapid respiration, pain and evidence of commencing consolidation of a portion of lung, but on the next day the symptoms have subsided and the patient makes a rapid recovery.

If, therefore, lobar pneumonia may occur in all degrees of severity from such a transient congestion to almost complete consolidation of one or both lungs, "grey hepatisation," and death, it would seem probable that acute nephritis may occur in varying degrees of severity and duration; that many recover, but that others pass on to chronic parenchymatous or interstitial nephritis, and it may be predicted that this will be the ultimate result in the series of cases discorered in Northern France.

It may be said that the analogy between lung and kidney is not correct because in pneumonia certain specific micro-organisms are usually found, but that hitherto all attempts to prove that acute nephritis is due to one or more specific bacteria have resulted in failure. Such a micro-organism may be discovered, but it is evident that some lesion must be produced in an organ before a hitherto quiescent bacterium can be "activated."

It is known that the majority of adults have in their upper respiratory tract Gram-positive diplococci, morphologically indistinguishable from pneumococci, and yet a large number of such persons pass through life without an attack of pneumonia. Such immunity shows that the mere presence of the diplococcus is not the determining factor in the causation of pneumonia. Over-exer. tion, chilling of the body surface causing rise of blood pressure, internal congestion, and local hæmorrhage may prepare a suitable nidus, in one case in the lung for the pneumococcus, and in another for a (?) streptococcus in the kidney, and the infection or non-infection of the lesion by the specific bacterium may decide whether the transient congestion will subside or develop as pneumonia or acute nephritis.

These conditions-over-exertion and "chill"are ever present among large bodies of troops at the front and they were found in Professor Edgeworth's cases and in those now published.

Clifton.

Chardes Edwin Matthews, M.D. Durh., L.R.C.P. EdIN., M.R.C.S.-Dr. Charles Edwin Matthews died at his residence, St. Aubyn's Park, Tiverton, on August 4th, in his sixty-fourth year, from heart failure following an operation. The deceased received his medical education at Bristol and University College, London, taking the M.R.C.S. in 1875 and the L.R.C.P. Edin. in 1877. He graduated M.D. of Durham University in 1896. Dr. Matthews was for many years in practice at Bristol, where he was highly respected; and about seven years ago he left Penarth and took up his residence at Tiverton, where he was school medical officer for the Tiverton education committee. He leaves a widow and four children. 